\title{
ASCENDING NERVE ROOTS
}

\author{
BY
}

\section{J. D. REID}

From the Pathology Department, Wellington Hospital, Wellington, New Zealand

The usual anatomical description of the course of the nerve roots is that they run transversely or slightly downwards in the neck, with increasing downward obliquity in the thoracic and lumbar regions. Three consecutive necropsy examinations of the spinal cord, however, unexpectedly showed that many roots might in fact run cephalically (Fig. 1). This paper extends and modifies a previous report (Reid, 1958) and records the direction of roots as found in $\mathbf{8 0}$ dissections in subjects $\mathbf{5}$ years of age and over. Evidence is presented to show that ascending roots may be radiologically demonstrable. The effects and significance of the anomaly are discussed.

\section{Terminology}

In this paper the individual filaments as they arise from the cord are termed "rootlets". From the points where they join to form bundles and evaginate the dura mater, they are called "roots", qualified if necessary by the description dorsal and ventral. From their points of fusion distal to the ganglia they are termed "nerves". Root pouches are the small funnels leading from the cord dura to the root sheaths. The term "cord dura" refers to the sheath around the cord as opposed to its extension around the roots or root sheaths. A segment of cord dura is its length from root to root, measured from the inferior border of roots at their origin from the cord dura.

\section{Materials and Methods}

Subjects were routine necropsy cases in a general hospital. With the exception of one Maori and one Hindu all were of European racial extraction. Some selection was exercised in that all available neurological cases with cord involvement and all young adults were included, while the very young and cases of gross spinal deformity were excluded. In older cases, dissections were made at random as time and circumstance permitted. Of the $\mathbf{8 0}$ subjects, 45 were males. After completion of the ordinary necropsy the subject was placed prone with the head over the end of the table. Muscles were dissected off the spines and laminae; the spines were removed as a preliminary operation to enable access by the vibratory saw which was then run up and down a short distance lateral to the base of the spines. Care was taken to

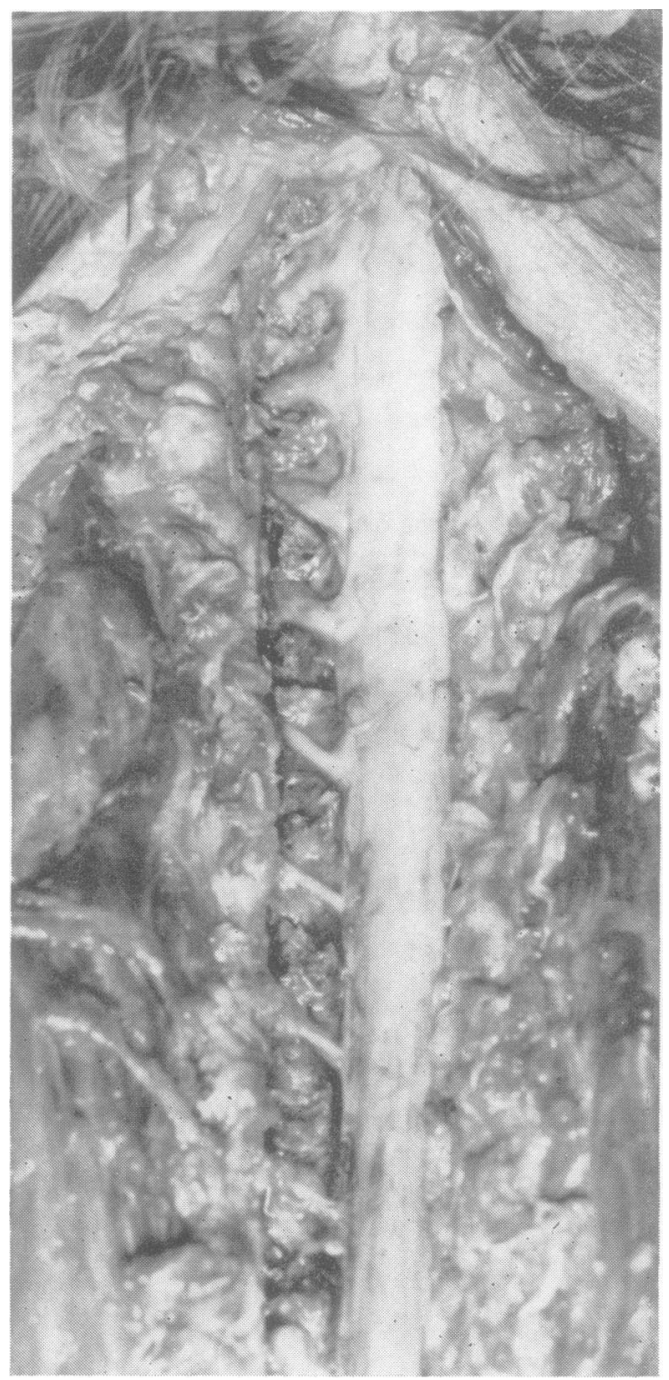

Fig. 1.-Case 64: Ascending roots, C8-T9.

prevent the blade slipping deeply into the canal and in most cases injury to roots was avoided or was minimal. Caudally, dissection extended at least to $\mathrm{L} 4$; in the neck 
TABLE I

SEX AND AGE DISTRIBUTION OF CASES WITH NORMAL AS OPPOSED TO TRANSVERSE OR ASCENDING COURSE OF NERVE ROOTS

\begin{tabular}{|c|c|c|c|c|c|c|c|c|c|}
\hline \multirow[b]{2}{*}{$\begin{array}{l}\text { Age Group } \\
\text { (years) }\end{array}$} & \multirow[b]{2}{*}{ Total Cases } & \multirow[b]{2}{*}{ Males } & \multirow[b]{2}{*}{ Females } & \multicolumn{2}{|c|}{ Males } & \multicolumn{2}{|c|}{ Females } & \multicolumn{2}{|c|}{ Both Sexes } \\
\hline & & & & Descending & $\begin{array}{c}\text { Ascending } \\
\text { or } \\
\text { Transverse }\end{array}$ & Descending & $\begin{array}{c}\text { Ascending } \\
\text { or } \\
\text { Transverse }\end{array}$ & Descending & $\begin{array}{l}\text { Ascending } \\
\text { or } \\
\text { Transverse }\end{array}$ \\
\hline $\begin{array}{l}5-15 \\
16-25 \\
26-35 \\
36-45 \\
46-55 \\
56-65 \\
66-75 \\
76 \text { and over }\end{array}$ & $\begin{array}{r}10 \\
9 \\
9 \\
13 \\
13 \\
12 \\
8 \\
6\end{array}$ & $\begin{array}{r}6 \\
6 \\
4 \\
11 \\
4 \\
7 \\
6 \\
6\end{array}$ & $\begin{array}{l}4 \\
3 \\
5 \\
2 \\
9 \\
5 \\
2 \\
4\end{array}$ & $\begin{array}{l}4 \\
3 \\
1 \\
2 \\
2 \\
2 \\
1 \\
0\end{array}$ & $\begin{array}{l}2 \\
3 \\
3 \\
9 \\
2 \\
5 \\
5 \\
2\end{array}$ & $\begin{array}{l}3 \\
2 \\
0 \\
0 \\
1 \\
0 \\
1 \\
1\end{array}$ & $\begin{array}{l}1 \\
1 \\
5 \\
2 \\
8 \\
5 \\
1 \\
1 \\
3\end{array}$ & $\begin{array}{l}7(70 \%) \\
5(55.5 \%) \\
1(11 \%) \\
2(15 \%) \\
3(23 \%) \\
2(17 \%) \\
2(25 \%) \\
1(16.6 \%)\end{array}$ & $\begin{array}{c}3(30 \%) \\
4(44.5 \%) \\
8(89 \%) \\
11(85 \%) \\
10(77 \%) \\
10(83 \%) \\
6(75 \%) \\
5(83.4 \%\end{array}$ \\
\hline Totals & 80 & 46 & 34 & 15 & 31 & 8 & 26 & $23(28.7 \%)$ & $57(71 \cdot 2 \%)$ \\
\hline
\end{tabular}

the upper two nerve roots were not usually examined, but all lower ones were exposed. Roots were identified from the first thoracic, which was usually clearly recognizable as the lowest of large size arising from the cervical enlargement. Generally, T12 was also identified, from its relation to the last rib. Twelve cases had neurological abnormalities related to the spinal cord. Five were examples of motor neurone disease, four of disseminated sclerosis, and one each of neuromyelitis optica, syringomyelia, and subacute combined degeneration. Bony abnormalities other than spondylotic changes were present in six cases. In Case 23 the disc space between T11 and 12 was lost and spines had been fused surgically. Secondary carcinoma was present in Case 14 without collapse and in Case 32 with partial collapse of L1. Fusion of posterior intervertebral lumbar joints was present in Case 12 and in Case 25 the entire thoracic and lumbar spine appeared fixed. In Case 74, together with platybasia and a defect in the posterior atlas, there was an unusually large foramen magnum.

The sex and age distribution of subjects examined is included in Table $\mathrm{I}$.

\section{Position of Head}

In all dissections, before making observations on the direction of roots, the head was carefully adjusted to a position considered to represent that of normal erect posture. The importance of this lay in the up-and-down movements of roots and marked changes in their direction induced by flexion-extension movements of the head and spine. In some instances, and particularly in children, the lower cervical roots could readily be made to run cephalically or caudally with small changes in position of the head. In the newborn and in infants, difficulties in deciding what was normal posture and consequently what was a proper description of the course of cervical roots, were so great that children below the age of 5 years were excluded from this series. As a further consequence it seemed unjustifiable to attempt measurement of angles formed between roots and cord dura, and note was therefore made only of roots running transversely or cephalically as opposed to the accepted normal caudal direction. It is realized that other observers might have adopted slightly different positions of the head as normal; any error by comparison with anatomical drawings of the erect spine was in the direction of insufficient extension. Since extension tends to increase the number of ascending roots, it is felt that abnormalities are conservatively recorded.

\section{Results}

The number of cases with any ascending or transversely directed roots as opposed to those with descending roots at all points is shown in Table $I$. Only $29 \%$ of all cases conformed to normal description, while $71 \%$ showed an "anomalous" direction in some section of the spine. Relation to sex and age is also shown. A sharp difference is apparent between those cases below and those over the age of 25 years. Whereas $63 \%$ of the former showed descending roots at all points, only $18 \%$ of the latter did so. The proportion of cases affected reached its maximum between the ages of 26 and 35 years. In the majority of the younger age group the cervical roots ran very slightly downwards, somewhat more so in the lower neck, with increasing downward obliquity in the thoracic and lumbar regions.

The number of segments of dura with ascending roots has been plotted in relation to age in Fig. 2, including those where roots were affected on one side only, as well as the usual paired anomaly. Transverse roots have been marked " $T$ ". There is a suggestion that in old age fewer roots are involved. The amount of upward angulation in general conformed to the extent of the anomaly; that is, when many roots ran upwards there was a pronounced degree of angulation and a more marked downward shift of dura. This did not apply in all cases; in some, many roots might appear to be running just above the transverse direction, or a single root might show marked angulation. The maximum amount by which origins of roots were displaced below the 

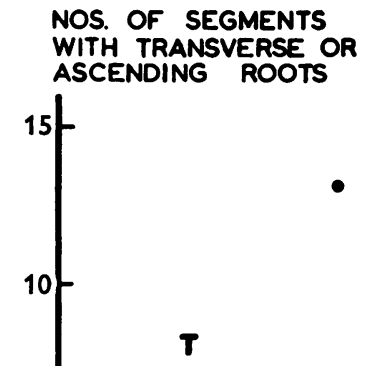

centres of their intervertebral foramina was $8 \mathrm{~mm}$., measured at $\mathrm{T} 5$ in Case 31 . The situation of ascending and transverse roots is shown in Fig. 3. The most commonly affected roots were those from C8 to T9 (Table I). The eighth cervical nerve was involved in $27.5 \%$ of cases, the seventh in $12.8 \%$, and the sixth in $10.2 \%$ of cases. In Cases 1 and 2
Fig. 2.-Extent of the anomaly in relation to age. Each point represents the number of segments of dura from which one or both roots ran transversely or cephalically.

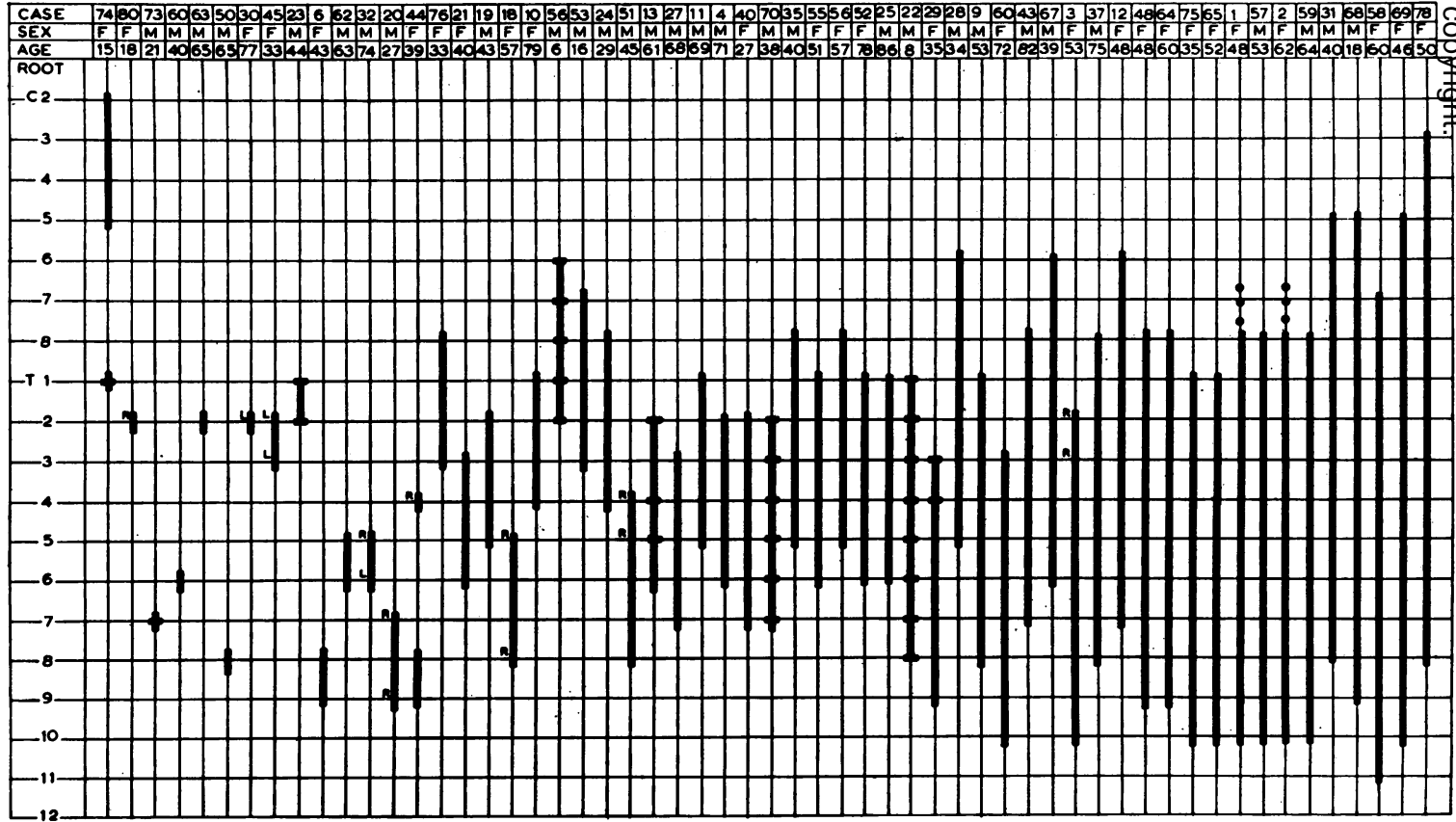

Fig. 3.- Situation and number of segments of dura causing ascending or transverse roots. Transverse bars indicate transverse roots. Small letters indicate roots involved on one side only. Upper limits were not determined in Cases 1 and 2.

the uppermost limit was not determined. In Case 74 there were ascending roots at $\mathrm{C} 2, \mathrm{C} 3$, and $\mathrm{C} 4$, apparently related to the condition of platybasia with a large foramen magnum and posterior defect in the atlas; roots $\mathrm{C} 5$ to $\mathrm{C} 8$ ran slightly caudally while $\mathrm{T} 1 \mathrm{again}$ was horizontal and lower roots ran acutely downwards. 
TABLE II

PERCENTAGE OF ROOTS WITH ASCENDING OR TRANSVERSE DIRECTION AT DIFFERENT LEVELS

\begin{tabular}{|c|c|c|c|c|c|c|c|c|c|c|c|c|c|c|c|}
\hline Root & C5 & 6 & 7 & 8 & T1 & 2 & 3 & 4 & 5 & 6 & 7 & 8 & 9 & 10 & 11 \\
\hline No. ascending or transverse & 4 & 8 & 10 & 22 & 33 & 42 & 41 & 40 & 40 & 36 & 28 & 24 & 17 & 9 & 1 \\
\hline Percentage & $5 \cdot 1$ & $10 \cdot 2$ & $12 \cdot 8$ & $27 \cdot 5$ & $41 \cdot 2$ & $52 \cdot 5$ & $51 \cdot 2$ & 50 & 50 & 45 & 35 & 30 & $21 \cdot 2$ & $11 \cdot 2$ & - \\
\hline
\end{tabular}

Above root $\mathrm{C} 8,78$ cases. $\mathrm{C} 8$ and below, 80 cases.

\section{Radiological Demonstration}

In an attempt to demonstrate the ascending course of nerve roots before dissection, watersoluble radio-opaque medium was injected into the lumbar space in six cadavers and radiographs were taken of the thoracic and cervical spine. Ascending roots in the thoracic region were readily shown radiologically with the subject supine. Considerable difficulty was experienced in demonstrating them in the neck, and the anterior direction of cervical roots and the cervical lordosis made it necessary to inject dye in the prone position. Results, however, were unsatisfactory and it was apparent that facilities available in the necropsy room were inadequate and that screening would be necessary. A second approach was to survey

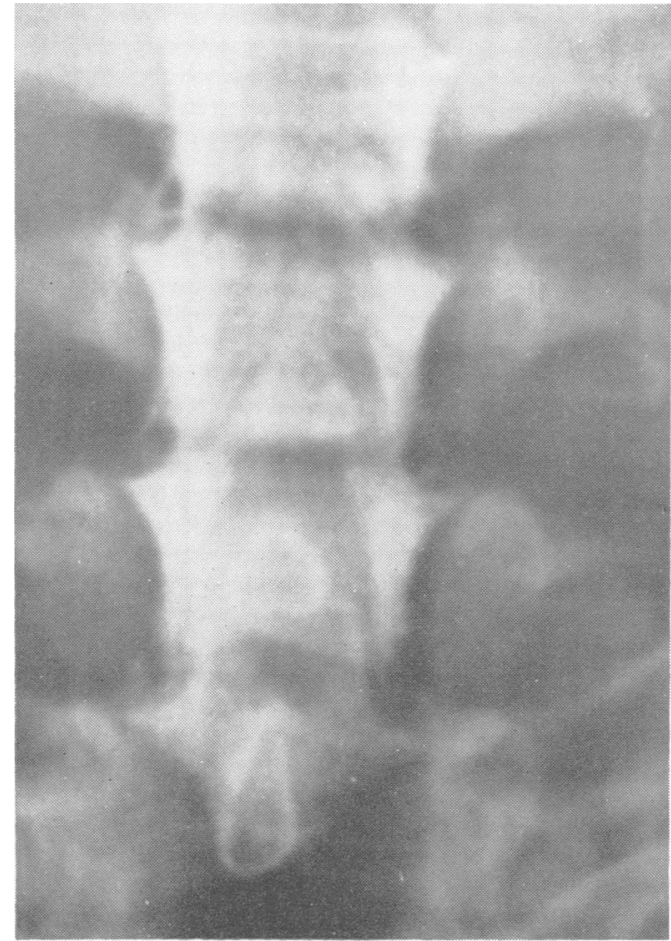

FIG. 4.-Cervical myelogram : Male aged 18 years (head extended). Clinical diagnosis: probable syringomyelia (case of Dr. J. Bergin). The descending rootlets can be seen, while the roots must run cephalically to pass through their intervertebral foramina.

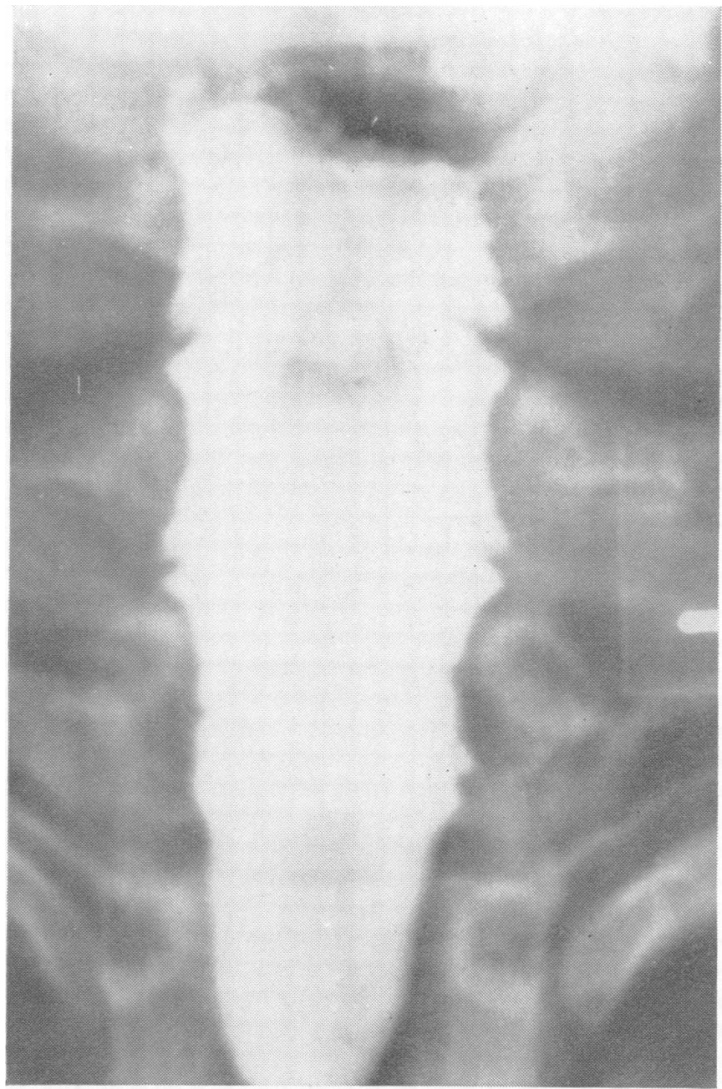

FIG. 5.-Myelogram for comparison, with descending roots.

cervical myelograms already available in the Radiology Department. It seemed from examination of these that the course of the cervical nerve roots could be inferred from the position of the root pouches in relation to the pedicles and intervertebral foramina (Fig. 4). Frykholm's (1951b) observations that the cervical roots did not show the same prolongation of arachnoid space as seen in lower roots appeared to be correct.

\section{Discussion}

Although ascending nerve roots were described by Baldwin in 1908, subsequent references to them are few and concern their occurrence in the lower cervical region, as described in particular by 
Frykholm (1951a and b), with the Arnold-Chiari malformation (Barry, Patten, and Stewart, 1957), and in Pott's disease (Seddon, 1956).

Descriptions of the direction of cervical roots based on dissections of fixed excised cervical spines, as in most of Frykholm's necropsy material, and in those of Payne and Spillane (1957), do not properly define their normal position since there is considerable up-and-down movement with flexion of head and neck. Any description must, therefore, be in relation to a stated posture. Further, formalin fixation produces dural shrinkage from each free end.

Observations presented here admittedly have the disadvantage of being based on post-mortem material with consequent inability accurately to reproduce living posture. Nevertheless, it appears probable that under the circumstances of the dissection, a reasonable approximation to the living position is achieved. If this is accepted then ascending roots appear to be an extremely common finding almost suggesting a physiological or ageing change in adults.

The difference between younger and older age groups, as can be seen from Fig. 2, is not only one of incidence, but also of extent. Of the seven cases affected below the age of 25 years, one pair of roots only was involved in two subjects. In another two, aged 6 and 8 years, the transverse direction of roots probably represented a minor variation in differential rates of growth between spine and dura and could not at such ages be certainly regarded as abnormal. In a fourth case, ascending roots at $\mathrm{C} 2,3,4$, and 5 appeared due to the anatomical anomaly of platybasia and of absence of the posterior arch of the atlas. Only in the remaining two were changes extensive and really comparable to those in adults. However, in these pathological changes were present. In Case 53, a male haemophiliac aged 16 years, the dura was tightly bound to the disc T11-12 and in Case 68 the subject, a male aged 18 years, had been an asthmatic since childhood and had a marked thoracic kyphosis.

The incidence of ascending or transverse cervical roots as found here differs considerably from that given by Frykholm for roots $\mathrm{C} 6, \mathrm{C7}$, and $\mathrm{C} 8$. In his dissections of 18 adult cervical spines (13 of which had been excised) the percentage of transverse and upwardly directed roots was 33,39 , and 69 respectively (1951b). In his series of 30 operation cases, chiefly 30-60 years of age, observations on the direction of 44 roots are available in his Table I (1951a). Again, combining ascending and transverse roots, the figures for roots $\mathrm{C} 6, \mathrm{C} 7$, and $\mathrm{C} 8$ are $73 \%, 83 \%$, and $80 \%$ respectively. However, the position of the head is not stated. Frykholm (1951b) had concluded that ventroflexion of the neck resulted in only very slight upward movement of the dural sac, so that angulation of nerves remained largely unaffected and conditions in adults could be regarded as practically constant. These conclusions cannot be accepted and possibly failure to make allowance for movement may account for some of the difference between his and the present findings. As previously stated, any error in the present work in adjusting posture to normal lies on the side of insufficient extension with conservative results. It is further conceded that in many cases very little more extension would have so altered the direction of the lower cervical roots that they would have been differently classified.

\section{Cause}

Ascending roots are obviously only a manifestation of the fact that their origins at the cord dura are lower than their corresponding intervertebral foramina. Several mechanisms can be conceived whereby such a relationship might be found in normal erect posture. These include $(a)$ deviation from normal differential rates of growth between spine and dura; (b) an acquired downward displacement of dura due to traction on, or contraction within, its lower section; (c) a passive "fall" of dura and cord within the canal, due either to their lengthening, or to shortening of the spinal canal, or $(d)$ an increase in length of the canal itself with a shift in position of the cord and dura.

(a) As one possibility the concept of failure in differential rates of growth has been advanced by Frykholm (1951b). However, the present series of cases demonstrates that the anomaly develops chiefly between the ages of 25 and 40 years, whereas it is known that full adult stature and maximum growth of spine are attained by the age of 24 years. The proportion of cases found to have ascending roots in young age groups was $38 \%$ and this included some where recognizably pathological causes were operating as discussed above. It seems fair to assume, therefore, that no greater proportion could, in ages over 25 years, be due to abnormal developmental and growth factors. Somewhat more than half of the $82 \%$ of anomalous cases in these latter age groups must be acquired in nature and probably very few are due solely to deviations in differential rates of growth.

(b) The possibility of a downward displacement of the lower end of the dural sheath has been reasonably well eliminated by establishing that in 28 anomalous cases the level of origin of the third lumbar nerve bore its normal relation to the intervertebral foramen when compared with 12 normal cases (Reid, 1958). 
Primary contraction of certain segments of dura seemed probable in some cases. Thus in Case 50 a single ascending root at $\mathrm{T} 8$ was situated above a demonstrably short segment of dura, as illustrated previously (Reid, 1958). Ordinary observation has repeatedly suggested that segments of dura below a group of ascending roots are shorter than the corresponding sections of spinal canal as measured between intervertebral foramina. However, such shortening could be relative or apparent only and actually due to a local increase in length of the canal. In four cases in which careful measurements were made (Reid, 1958), the dura was found to be shorter than the corresponding length of spine and in two of these such shortening was irregular and varied in amount in adjacent segments of dura, suggesting a primary contracture. However, no cause was apparent and microscopic sections of different parts of dura were unrevealing. The presence of ascending roots above the kyphus in Pott's disease is confirmatory evidence that inflammatory fibrosis and shortening may indeed be causal factors, and similar mechanisms may operate in cases where the dura is adherent to protrusions from the anterior wall of the canal. However, in the present dissections such changes were found in four cases only. In quite a number, the lower thoracic and lumbar dura appeared rather firmly but diffusely attached to the posterior ligament so that it could not be readily stripped out of the canal. The cause was not apparent.

(c) With normal flexion of the head and neck, there is considerable stretching of the cord and dura, particularly between roots $\mathrm{C} 2$ and $\mathrm{T} 1$, as is shown in a following paper (Reid, 1960). It is conceivable that these segments might actually become elongated with repeated stresses over many years and that the thoracic cord and dura would be displaced downwards by a passive fall. In such cases the dura might be expected to be slacker than normal, but this was not noticed in younger ages where a normal or increased tension was the rule. It was suggested by Frykholm (1951b) that a passive fall of dura and cord might follow degeneration of cervical discs. The degree to which this might be offset by other ageing changes such as straightening of the cervical lordosis cannot be calculated but it would seem probable that such shortening of the upper spinal canal might at least be a contributory factor in older age groups. It is less easy to accept this as the primary mechanism in the ages of 25 to 40 years when the anomaly chiefly develops.

(d) Changes which occur in the overall length or in the length of different sections of the spinal canal at different ages do not appear to have been examined in detail. As mentioned, the cervical lordosis is said to straighten with age (Payne and Spillane, 1957) and a thoracic kyphosis may appear as early as 30-35 years (Weston, 1959). Both of these changes resemble flexion of the spine which may readily be shown to increase the length of the canal by its effect in augmenting tension of the cord and dura. However, it is not certain that ageing changes have the same result since they may be counterbalanced to some degree by degenerative shortening of vertebrae and discs. In early adult life it seems probable that with kyphosis the canal may undergo some lengthening.

With such increase in length, the dura must either stretch or move bodily upwards. From the normal position of the third lumbar nerve root, in observations already quoted, it may be accepted that the dura does not move cephalically and it follows that stretch must occur. Should this result in a local elongation or "give" rather than a more diffusely distributed stretching, then segments below will show a downward displacement within the canal and, if this is of sufficient degree, ascending roots. The section of dura and cord which is subject to most frequent and most severe stretching is that between roots $\mathrm{C} 2$ and $\mathrm{T} 1$ and an actual elongation here would not be surprising under increased tension from a lengthened canal. Such a hypothesis would explain why, in cases with ascending roots, the upper limit of the anomaly appears in general to lie in the lower cervical region. If the length of the canal were increased locally due to upper thoracic kyphosis, then the picture as generally seen (Fig. 3) would be adequately explained. To account for those cases where only mid-thoracic roots are involved, it would be necessary to postulate a lower thoracic kyphosis and a "give" in the dura just above. The first of these conditions is not unreasonable since radiological evidence suggests that the thoracic kyphosis of age may first appear in the lower rather than the upper thoracic spine (Weston, 1959).

Of the possible mechanisms which have been discussed, it may be said in summary that developmental factors are probably by themselves an uncommon cause of ascending roots; that local inflammatory contraction of dura has been infrequently demonstrated; that passive fall of the dura and cord from degeneration of the cervical spine seems unlikely in the age group at which the anomaly chiefly appears; and that the frequency of the condition in young adults suggests some postural alteration rather than gross pathological change.

In any one case, more than one factor may be operating, but of such the most frequent may well be changes in length of the spinal canal with local elongation of the dura and cord and a downward 
shift of their positions relative to the intervertebral foramina.

\section{Effects}

The great majority of cases in this series was neurologically normal, as ordinarily understood, and ascending roots did not appear by themselves to have caused symptoms or pathological changes. Nevertheless it seems probable that by their altered position and closer apposition to the inferior bony margins of the foramina they may be liable to damage, particularly in the lower cervical region where movements are considerable and protrusions into the foramina or within the canal are not infrequent. The downward pull on nerves from a drooping shoulder girdle (Allen, 1952) would be more than usually likely to do harm, since roots would tend to be pulled up and over the rims of their foramina. Symptoms similar to those of cervical spondylitis might result, as Frykholm (1951b) has suggested in his discussion of root sleeve fibrosis. In the thoracic region ascending roots have the same direction as the nerves running upwards beneath the ribs, and do not turn down over the pedicles as do those entering the brachial plexus (Fig. 6). Further, lateral movements do not occur. Nevertheless a predisposition to radiculitis may remain and this may be of some significance in the aetiology of fibrositis.

Ascending cervical roots might also imperil the blood supply to the cord. In this region, only one major arterial contribution is made to the anterior spinal artery along any one of the roots C6 to C8 (Woollam and Millen, 1958) and should this root be in contact with its bony pedicle, then the artery might conceivably undergo intermittent compression or spasm or even thrombosis. Extensive cord changes could result.

It is also possible that the mechanisms which result in an upward direction of roots may themselves be responsible for damage to the cord, of which ascending roots may be, as it were, an indicator. The cord and its dural sheath are attached by the ligamenta denticulata and move together in an up-and-down direction. It can be inferred, therefore, that if the dura has been displaced downwards, so has the cord. If such displacement has been facilitated by shortening of the upper spinal canal, no abnormal stresses need have occurred, but if the upper dura has been abnormally stretched and increased in its actual length, then it would seemo that the cord has also been stretched and possibly made more vulnerable to compression or intrinsic disease processes. The first case in which ascending roots were noted was a woman of 48 years with a clinical diagnosis of amyotrophic lateral sclerosis, who was noticed to have a marked thoracic kyphosis, whose dura was unusually tight and was adherent to the posterior common ligament in the lumbar region, and whose cord (after fixation) was found to show indentations corresponding to small osteophytic and disc protrusions. These indentations, as shown by Payne and Spillane (1957), may well have been artefactual and not present in life. Nevertheless, the possibility remains that the increased tension of the cord and dura may have been a factor in the development of pathological changes.

A proper evaluation of the role of ascending roots 
in the production of neurological signs and symptoms will require clinical, radiological, and pathological correlation, taking into consideration other factors at present held to be major causes of pathological change.

\section{Summary}

The direction of nerve roots has been investigated in a series of 80 dissections in subjects over the age of 5 years, with a standardized position of the head relative to the trunk. Under these conditions ascending roots have been found in $71 \%$ of all subjects, with a significantly lesser incidence $(38 \%)$ in those below the age of 25 years than in those older $(82 \%)$. The anomaly appears to develop in early adult life, chiefly between the ages of 26 and 35 years and does not increase in frequency in older groups. In extent it is maximal between 40 and 60 years of age. The upper and mid-thoracic regions are most often affected. The cause is uncertain and multiple factors are probably involved, differing with different age groups. Adjustments in position of the dura and cord due to alterations of spinal curvature and length of spinal canal are probably most commonly responsible. Inflammatory fibrosis and adhesions with localized dural contraction may be factors in some cases, while others may be the result of a deviation from normal differential rates of growth between the dura and the spine. The possible effects of an ascending direction of roots are discussed, particularly in terms of direct damage to cervical roots or indirect damage to the cervical cord by interference with the radicular contribution to the anterior spinal artery. In some circumstances the upward direction of roots may be an indication of abnormal stretching of the dura and cord, making the latter unduly susceptible to pathological processes.

Acknowledgement is made of assistant and advice from many colleagues, particularly Dr. J. D. Bergin, Mr. A. W. Beasley, Dr. J. D. Manning, and Dr. W. J. Weston, Wellington, and Dr. W. D. Trotter, of the Anatomy Department of the University of Otago Medical School.

\section{REFERENCES}

Allen, K. L. (1952). J. Neurol. Neurosurg. Psychiat., 15, 20. Baldwin, W. M. (1908). Anat. Rec., 2, 155

Barry, A., Patten, B. M., and Stewart, B. H. (1957). J. Neurosurg., 14, 285.

Frykholm, R. (1951a), Acta chir. scand., Suppl. 160

(1951b), Ibid., 101, 457.

Payne, E. E., and Spillane, J. D. (1957). Brain, 80, 571

Reid, J. D. (1958). N.Z. med. J., 57, 16.

- (1960). J. Neurol. Neurosurg. Psychiat., To be published.

Seddon, H. J. (1956). In Modern Trends in Orthopaedics (2nd Series) ed. H. Platt. Butterworth, London.

Weston, W. J. (1959). Personal communication.

Weston, W. J. (1959). Personal communication.
Woollam, D. H. M., and Millen, J. W. (1958). Proc. roy. Soc. Med., 51,540 . 